J. Lake Sci. (湖泊科学) , 2007, 19(5) :585-591

http:// www. jlakes. org. E-mail: jlakes@ niglas. ac.cn

(c) 2007 by Journal of Lake Sciences

\title{
汉江流域上游支流大型底栖动物群落结构特征与生物多样性”
}

\author{
间云君, 李晓宇 \\ (华中科技大学生命科学与技术学院,武汉 430074)
}

摘 要:2003 年 6 月至 2004 年 6 月, 对汉江流域上游支流——黑竹冲河的大型底栖动物群落结构与生物多样性进行了深 人研究,结果表明: 河流生物群落结构和生物多样性比较复杂, 河流功能状况良好. 在采集到的 85 种大型底栖动物中, 昆 虫占 71 种; 群落表现出明显的时空特点, 具边缘效应的第 4 采样点物种最丰富, 2 月份物种最多,达 50 种; 生物多样性指 数周年动态显示, 第 1 采样点的物种多样性变动最为平稳, 第 5 采样点变动最大, 其它各点居中; 各微生境中共有种占据 优势, 物种相似性均大于 $60 \%$; 群落春季的多样性高于夏季, 夏季高于秋季; 功能摄食群则以收集者占优, 共计达 68 种. 群落密度在 1 月份达到最大,为 $1843 \mathrm{ind} / \mathrm{m}^{2}$; 而生物量则在 10 月份达到最大, 为 $228.7393 \mathrm{~g} / \mathrm{m}^{2}$.

关键词: 汉江流域; 大型底栖动物; 群落结构;生物多样性

\section{Community structure and biodiversity of macrozoobentos in a tributary of upper reaches of Hanjiang River}

\author{
YAN Yunjun \& LI Xiaoyu \\ (College of Life Science and Technology, Huazhong University of Science and Technology, Wuhan 430074, P. R. \\ China)
}

\begin{abstract}
The community structure and biodiversity of macrozoobenthos in lower grade river - Heizhuchong stream of Hanjiang River Basin was investigated from June, 2003 to June, 2004. The results showed that the community structure and biodiversity was complex, which indicates that the ecological function of the stream goes well. Among the collected 85 species, 71 were insect species. The community structure exhibited an obvious spatial and temporal variation, Site 4 with fringe effect possessing the most species, and in February there existed 50 species, much more than those in other months. The annual dynamics of biodiversity indexes suggested that Site 1 kept more stable and Site 5 appeared more variable than those in other sites. More than $60 \%$ of the collected species could inhabit in six different microhabitats. Biodiversity in spring was much greater than that in summer, and that in summer was yet greater than that in fall. Based on Wetzel's functional feeding group concept, $80 \%$ community species were gathering-filtering collectors. The density of the community reached its peak at $1843 \mathrm{ind} / \mathrm{m}^{2}$ in January, and biomass attained its peak at $228.7393 \mathrm{~g} / \mathrm{m}^{2}$ in October.
\end{abstract}

Keywords : Hanjiang River Basin; macrozoobenthos; community structure; biodiversity

大型底栖动物是河流生态系统中重要生态类群,在水底起着加速碎屑分解、促进泥水界面物质交换和 水体自净的作用, 是河流生态系统物质循环和能量代谢重要的环节, 也是了解河流生态系统结构和功能及 健康状况的关键类群. 此外, 河流大型底栖动物作为重要的指示生物, 已广泛应用于水质及环境监测, 起着 水下哨兵的作用 ${ }^{[1]}$. 目前河流大型底栖动物群落结构与功能特征成为水体环境质量生物监测研究的热 点 ${ }^{[2]}$. 在我国, 河流的功能 (物质循环和能量流动) 生态学研究尚属起步阶段, 工作少而零散,随着我国对河 流水电的大规模开发、河流环境的污染恶化,使河流可持续利用问题变得日益尖锐突出. 因此,加深对我国

* 国家自然科学基金( 30270278 )资助项目.2006-08-14 收稿;2006-10-13 收修改稿. 间云君,男,1969 年生,博 士,教授;E-mail: yanyunjun@ tom.com. 
河流生态系统结构包括生物多样性和功能的认识与了解, 对制订适合我国河流状况的综合生物监测体系, 提出污染河流治理、恢复和保护的有效对策具有非常重要的理论意义. 本论文报道的是作者于 2003 年至 2004 年间对汉江流域上游一支流大型底栖动物群落结构和生物多样性的研究结果, 主要目的是利用大型 底栖动物群落结构和功能特征对汉江上游河流的水环境健康状况作出客观评价, 为汉江河流的水质保护提 供理论指导和资料支持.

\section{1 工作方法}

\section{1 采集点和采样时间}

位于汉江上游流域的湖北省襄樊市南漳县城关镇附近有三条相邻河流,其中黑竹冲河受到污染较少, 选择作为研究地点, 其河水的理化性质见表 1 (年均值). 根据河流生境类型从上游至下游选择了 6 个采样 点(图 1), 分别是:1 站 $\left(S_{1}\right)$ 位于上游河心的大圆石块区域;2 站 $\left(S_{2}\right)$ 位于一堰塘内, 基底为砾石;3 站 $\left(S_{3}\right)$ 位于缓流河段中心点, 少数砾石半没于泥砂中;4 站 $\left(\mathrm{S}_{4}\right)$ 位于河边生长水草的区域;5 站 $\left(\mathrm{S}_{5}\right)$ 位于急流中心 的大石块区; 6 站 $\left(\mathrm{S}_{6}\right)$ 位于一间歇排污口的下游, 为泥沙底, 每个采样点间距约为 $1000-1500 \mathrm{~m}$, 样点大小 为 $30 \mathrm{~cm} \times 30 \mathrm{~cm}$. 采样时间一般在每月 28 日左右, 为期一年, 即 2003 年 6 月至 2004 年 6 月.

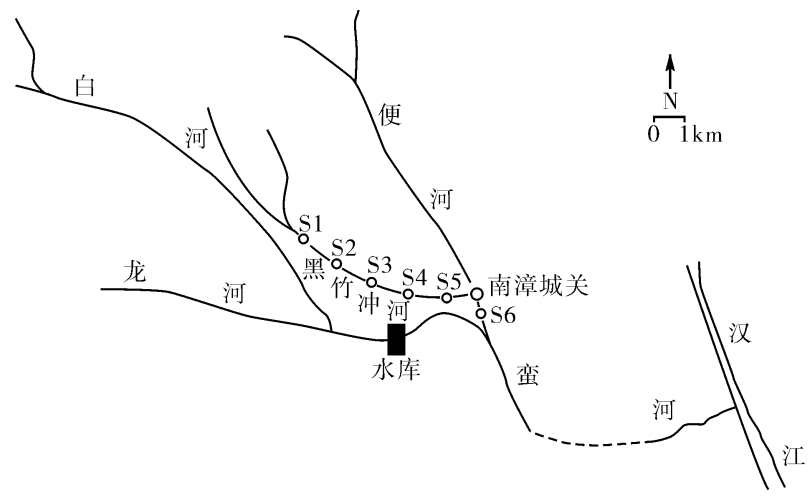

图 1 黑竹冲河及采样点的分布

Fig. 1 Distribution of sampling sites at Heizhuchong stream, Hanjiang River

表 1 黑竹冲河河水理化性质

Tab. 1 Main physical and chemical characteristics of Heizhuchong stream

\begin{tabular}{|c|c|c|c|c|c|c|c|c|c|}
\hline $\mathrm{pH}$ & $\begin{array}{c}\text { TDS } \\
(\mathrm{mg} / \mathrm{L})\end{array}$ & $\begin{array}{c}\mathrm{TP} \\
(\mathrm{mg} / \mathrm{L})\end{array}$ & $\begin{array}{c}\mathrm{TN} \\
(\mathrm{mg} / \mathrm{L})\end{array}$ & $\begin{array}{c}\mathrm{NH}_{4}-\mathrm{N} \\
(\mathrm{mg} / \mathrm{L})\end{array}$ & $\begin{array}{c}\mathrm{NO}_{2}-\mathrm{N} \\
(\mathrm{mg} / \mathrm{L})\end{array}$ & $\begin{array}{l}\mathrm{NO}_{3}-\mathrm{N} \\
(\mathrm{mg} / \mathrm{L})\end{array}$ & $\begin{array}{c}\text { DO } \\
(\mathrm{mg} / \mathrm{L})\end{array}$ & $\mathrm{COD}_{\mathrm{Mn}}$ & $\begin{array}{c}\mathrm{BOD}_{5} \\
(\mathrm{mg} / \mathrm{L})\end{array}$ \\
\hline 8.0 & 5.0 & 0.017 & 1.572 & 0.223 & 0.009 & 1.33 & 11.5 & 1.5 & 1.41 \\
\hline
\end{tabular}

\section{2 标本采集及处理}

定量采集使用 60 目的 D 型网或 Surber 网,每样点 1 次, 3 个重复; 样点 6 还增加了彼得森采泥器定量 采集泥样. 样品经 60 目铜笁耖洗后, 剩余物带回实验室, 置于白磁盘活体挑选, 标本以 $10 \%$ 福尔马林固定 保存. 标本经鉴定、计数和称重后, 换算成每平方米的含量.

\section{3 物种多样性的计算方法}

根据黑竹冲河大型底栖动物群落的特点及取样数据, 选择以下公式 ${ }^{[3]}$ 进行数据及结果的分析:

(1) Margalef 种类丰度指数: $D=(S-1) / \ln N$; (2) Shannon-Wiener 指数 $H^{\prime}=\sum_{i=1}^{S} P_{i} \ln P_{i}$; (3) Simpson 多样性指数 $D=1-\sum_{i=1}^{S}\left(P_{i}\right)^{2}$; 式中, $S$ 为总种数; $P_{i}$ 为 $i$ 种的个体数占总个体数的比例; $N$ 为所有种的个 
体总数.

\section{4 不同生境群落结构的比较}

采用双因素方差 (ANOVA) 检验各采样点之间大型底栖动物物种数及密度的差异, 同时采用 Sørensen 指数 $S=2 C /(a+b)$ (式中, $S$ 为相似性指数; $C$ 为两个群落共有的种数; $a$ 为 $S_{i}$ 站点大型底栖动物群落的物 种数; $b$ 为 $S_{j}$ 站点大型底栖动物群落的物种数) 比较各采样点大型底栖动物群落结构的差异, 用 $K$-优势曲线 的方法比较河流大型底栖动物生物多样性 ${ }^{[4]}$.

\section{2 结果}

\section{1 黑竹冲河大型底栖动物群落构成及动态}

共采集到大型底栖动物 85 种,其中扁形动物 1 种,环节动物 4 种, 缓步动物 1 种, 昆虫 71 种, 软甲动物 3 种,鱼 1 种. 总体上看, 由于该河流生态系统处于山区, 主要土地利用模式以农业和林业为主, 受到人为影 响特别是废水排放污染相对较小, 因此, 河流生态系统处于良好健康状态, 生物多样性和食物网结构比较复 杂,生态功能(包括物质循环和能量传递) 运转良好.

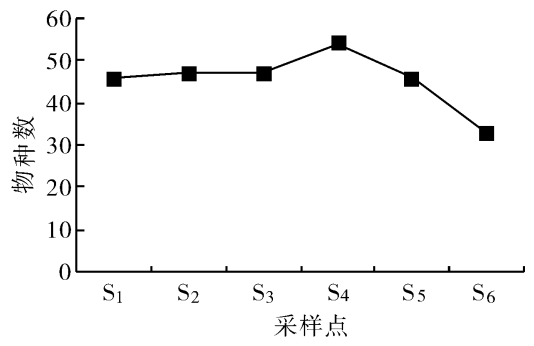

图 2 河流群落的空间动态

Fig. 2 Spatial dynamics of riverine zoobenthos community

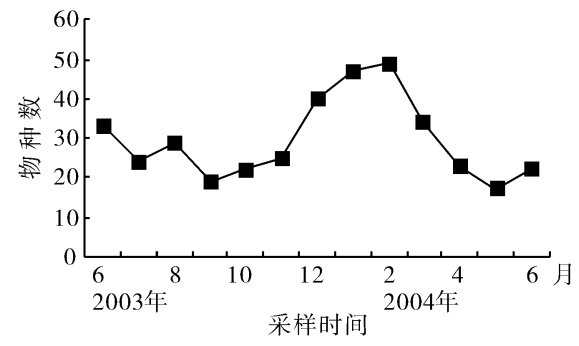

图 3 河流群落结构的时间动态

Fig. 3 Temporal dynamics of riverine zoobenthos community

2.1 .1 群落结构的空间动态 从空间上看, 在一年中各样点采集到的物种数如图 2 所示. 其中样点 4 采集 到的底栖动物种类最多, 共计 54 种. 这与样点 4 为河边生长水草的区域, 具边缘效应有关. 而 6 号采样站 种类最少, 原因是 6 号采样站位于一间歇排污口的下游且为泥沙底,生境单一且受污染干扰,多数环境敏感 种类不能生存.

2.1 .2 群落结构的时间动态 从时间上看,一年中采集到物种最多的月份出现在 2 月份, 这与冬季捕食者 冬眠 (鱼类) 或滞育 (蜻蜓幼虫等), 对河流底栖动物捕食压力低有关, 特别是少见种在 $1 、 2$ 月份出现较多. 相反, 在 5 月和 8 月少见种出现得比较少, 说明这些月份捕食者的捕食压力比较大.

\section{2 各微生境大型底栖动物群落生物多样性}

各微生境 (采样点) 的生物多样性指数的时间动态如图 4. 可以看出, 与其它二种多样性指数相比, Simpson 多样性指数变动幅度最大, 而且并不是任何时候与其它两种指数的变化趋势相吻合. 总体上, 第一 采样点的物种多样性变动最为平稳, 第五采样点变动最大, 其它各点居中. 这与第一采样点的物种种类和 密度相对稳定, 而第五采样点的则变动较大相吻合. 但从三种多样性指数来看, 比较适合反映黑竹冲河生 物多样性实际的指数应为 Marglef 指数和 Shannon-Wiener 指数.

\section{3 各种微生境群落相似性}

各微生境的 Sørensen 相似指数见表 2. 总体上,生活在各微生境中的共有种占据优势, 最小的相似性也 达到 $60 \%$. $\mathrm{S}_{1}$ 和 $S_{3} 、 S_{5}$ 和 $S_{3}$ 的相似性更高达 $80 \%$. 说明多数物种能够适应河流的多种微环境, 从某种意义 上保证了在干旱季节河流物种多样性的延续.

\section{4 群落 $K$-优势曲线的季节动态}

物种多样性可用 $K$-优势曲线比较, 它综合了物种多样性的两个主要方面一一物种丰富度和均匀性, 通 过对一特定群落内的各个物种 (按优势度从大到小排列) 相应的累计密度百分数作图, 群落的优势格局可 
以非常直观地表现出来. 如果某一曲线所有各点都位于另一曲线之下, 表明该曲线所表示的群落物种多样 性比另一曲线表示的群落高. 图 5 是各个季节中大型底栖动物群落的 $K$-优势曲线, 可以看出, 春季的群落 多样性要高于夏季, 夏季又要高于秋季; 冬季的也高于秋季, 但由于其 $K$-优势曲线与夏、春季节相交而无法 比较.
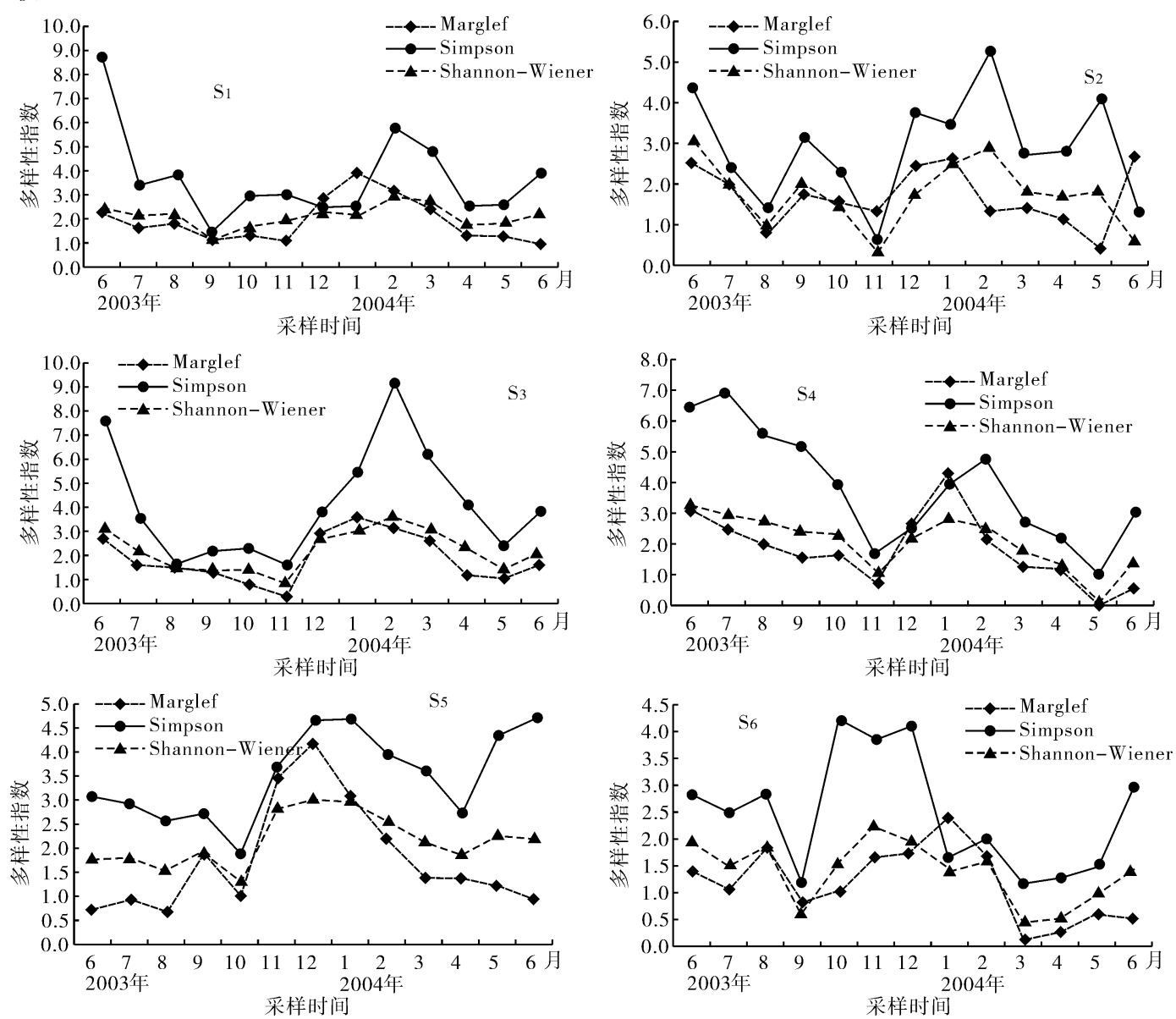

图 4 河流群落生物多样性指数的时间动态

Fig. 4 Temporal variation of biodiversity of riverine zoobenthos community

表 2 各种微生境的物种相似性

Tab. 2 Similarity of species between each microhabitat

\begin{tabular}{ccccccc}
\hline 站点 & $\mathrm{S}_{1}$ & $\mathrm{~S}_{2}$ & $\mathrm{~S}_{3}$ & $\mathrm{~S}_{4}$ & $\mathrm{~S}_{5}$ & $\mathrm{~S}_{6}$ \\
\hline $\mathrm{S}_{1}$ & 1 & - & - & - & - & - \\
$\mathrm{S}_{2}$ & 0.77 & 1 & - & - & - & - \\
$\mathrm{S}_{3}$ & 0.80 & 0.70 & 1 & - & - & - \\
$\mathrm{S}_{4}$ & 0.64 & 0.79 & 0.65 & 1 & - & - \\
$\mathrm{S}_{5}$ & 0.78 & 0.73 & 0.80 & 0.60 & 1 & - \\
$\mathrm{S}_{6}$ & 0.68 & 0.65 & 0.65 & 0.57 & 0.66 & 1 \\
\hline
\end{tabular}




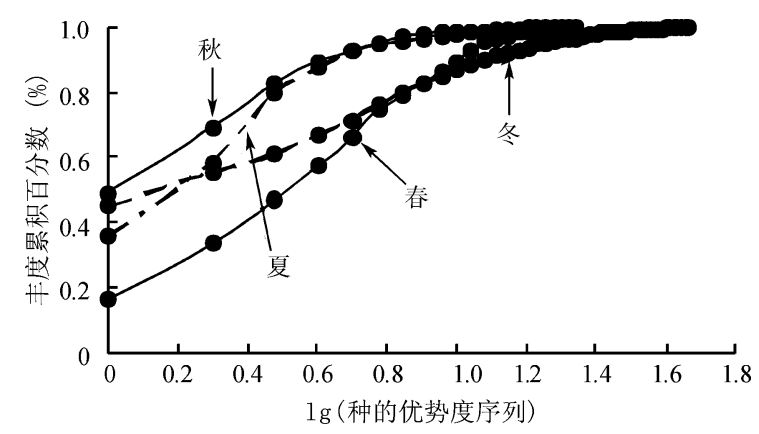

图 5 各季节的 $K$-优势曲线

Fig. $5 \mathrm{~K}$-dominance curve of various seasons

\section{5 功能摄食群}

按照 Wetzel ${ }^{[5]}$ 功能摄食群的划分标准,共有撕食者 (shredders) 5 种,收集者 (collectors) 68 种,刮食者 ( scrapers) 12 种,捕食者 (predators) 6 种. 各采样点功能摄食群物种分布见表 3.

表 3 各微生境大型底栖动物的功能摄食类群

Tab. 3 The functional feeding groups in various microhabitats

\begin{tabular}{ccccccc}
\hline 功能摄食类群 & $\mathrm{S}_{1}$ & $\mathrm{~S}_{2}$ & $\mathrm{~S}_{3}$ & $\mathrm{~S}_{4}$ & $\mathrm{~S}_{5}$ & $\mathrm{~S}_{6}$ \\
\hline 撕食者 & 2 & 2 & 1 & 5 & 1 & 0 \\
收集者 & 32 & 31 & 32 & 35 & 32 & 29 \\
刮食者 & 8 & 9 & 11 & 10 & 11 & 3 \\
捕食者 & 4 & 5 & 3 & 4 & 2 & 1 \\
\hline
\end{tabular}

\section{6 优势种现存量动态}

黑竹冲河大型底栖动物的优势类群包括蜉蝣, 优势种为扁蜉 (Epeorus sinensis (Umler))、细蜉 (Caenis nigropunctata $(\mathrm{Wu})$ ) 和蜉蝣属 (Ephemera sp.) 一种; 毛翅目昆虫, 优势种为纹石蛾 (Hydropsyche sp. ) ; 甲壳动 物, 优势种为华溪蟹 (Sinopotamon teritisum (Dai et al.)) ; 软体动物, 优势种为黄蚬 (Corbicula fluminea (Müller) ) ; 摇蚊, 优势种为杂色特维摇蚊 (Tvetenia discoloripes (Goetghebuer)) 和波特真开氏摇蚊 (Eukiefferiella potthasti ( Lehmann)). 各优势种的生物量周年动态如图 6.

\section{7 群落现存量动态}

黑竹冲河大型底栖动物群落现存量的周年动态如图 7. 从图 7 可以看出, 群落密度在 1 月份达到最大, 为 $1843 \mathrm{ind} / \mathrm{m}^{2}$; 而生物量则在 10 月份达到最大, 为 $228.7393 \mathrm{~g} / \mathrm{m}^{2}$; 其它月份则相对比较稳定. 密度和生物 量出现峰值不同步的原因在于, 大多数优势物种的密度在 1 月份达到最大, 而群落的生物量主要受黄蚬的 生物量影响,十月份黄蚬的生物量达到最大.

\section{3 讨论}

河流群落特别是底栖动物群落的结构和生物多样性是判别河流生态功能正常与否、健康与否的主要标 志. 因此, 河流底栖动物被作为重要的指示生物广泛应用于水质及环境监测上. 根据上述采集到的物种数 和物种多样性指数, 并结合群落 $K$-优势度曲线的季节动态, 参照生物评价水环境的相关研究方法 ${ }^{[6,7]}$, 可以 看出该河流水质比较清洁,与河水理化指标提示的状况较为一致性. 为此,该溪流的物种和生物多样性可 作为我国清洁河流的本底状况,为评价其它存在不同程度污染河流提供参考.

在对同一河流的不同微生境群落结构的比较中发现,约有 $60 \%$ 的物种可以适应生存于河流的各种微 生境, 其余约 $40 \%$ 的物种则在不同定程度上反映出微生境间的差异. 如样点 $6\left(\mathrm{~S}_{6}\right)$ 位于一间歇排污口的下 

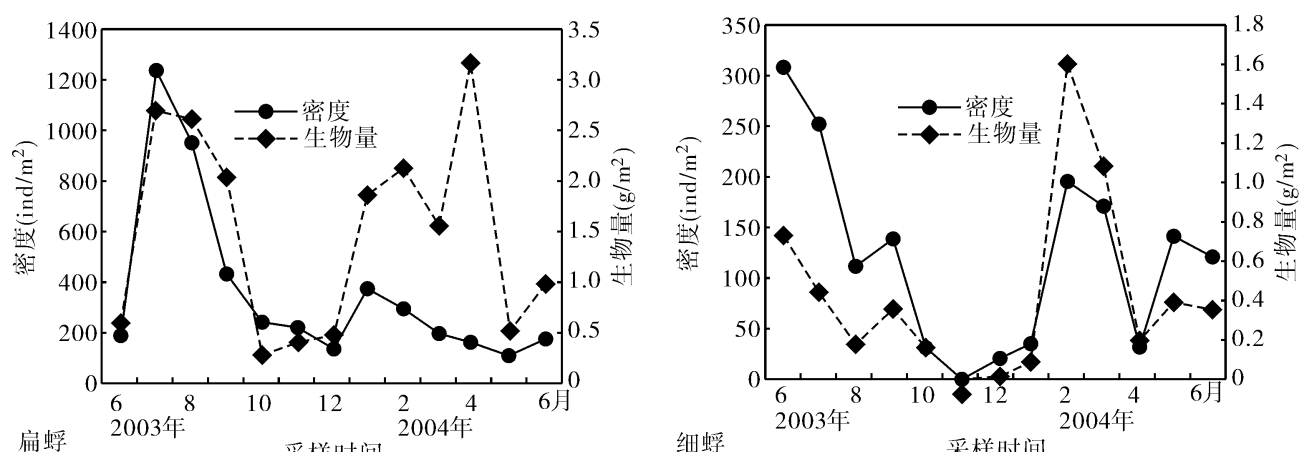

细蜉

采样时间

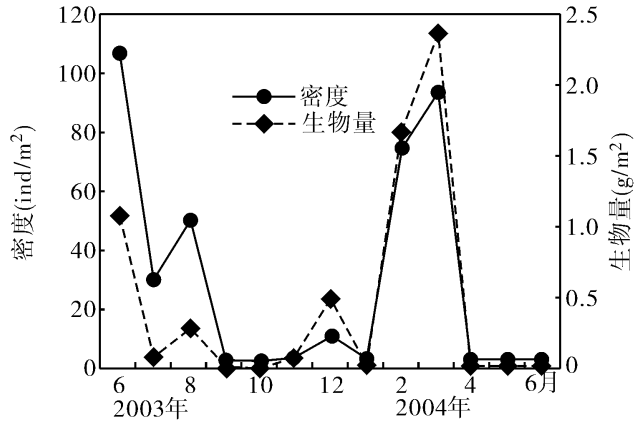

蜉蝣属一种采样时间
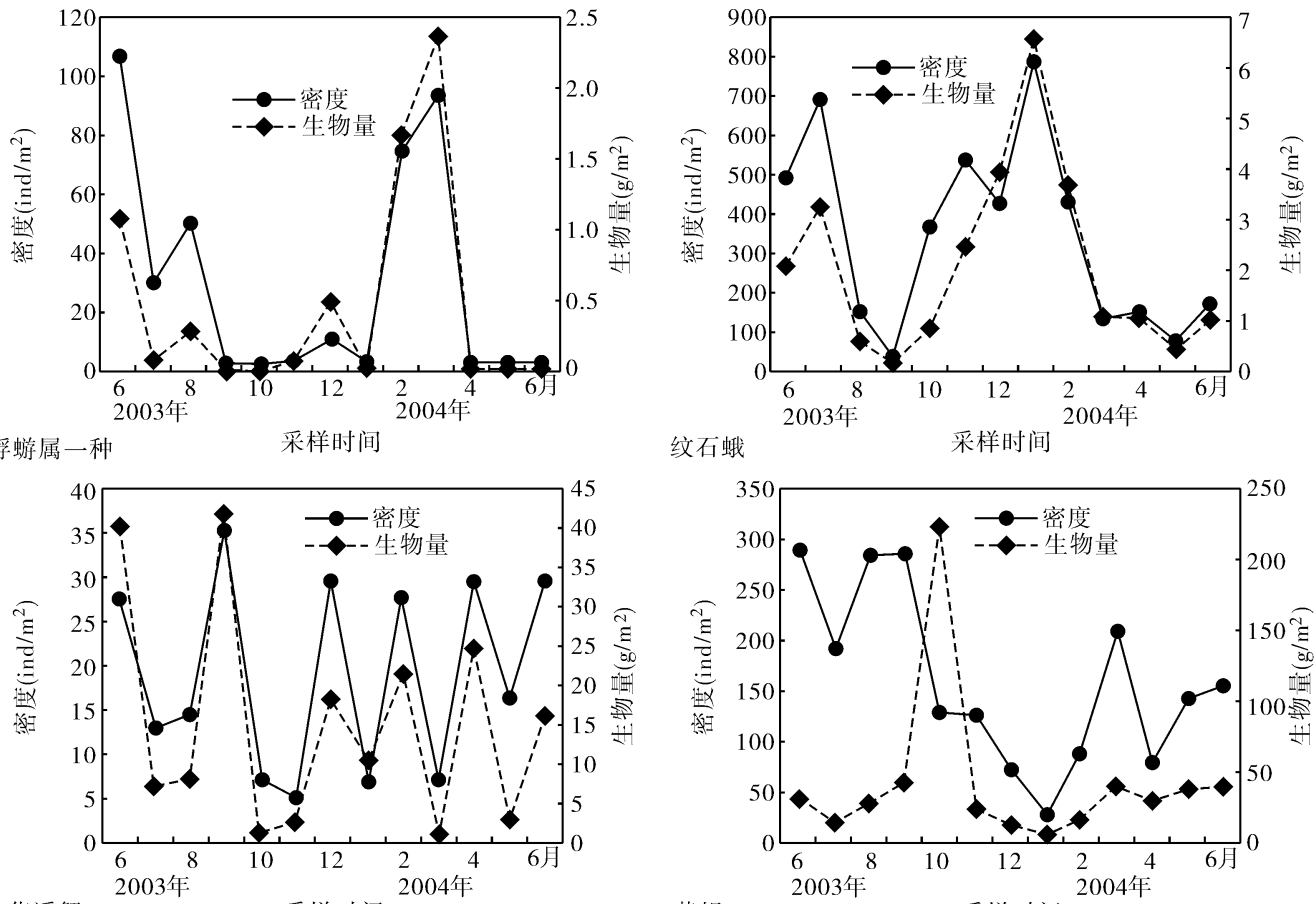

华溪蟹

采样时间

纹石蛾

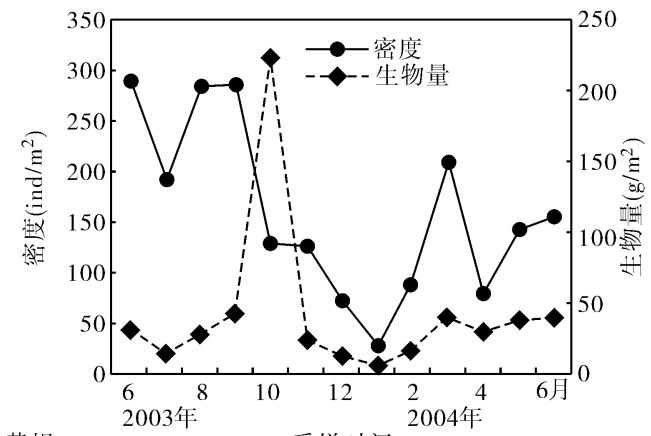

黄蚬
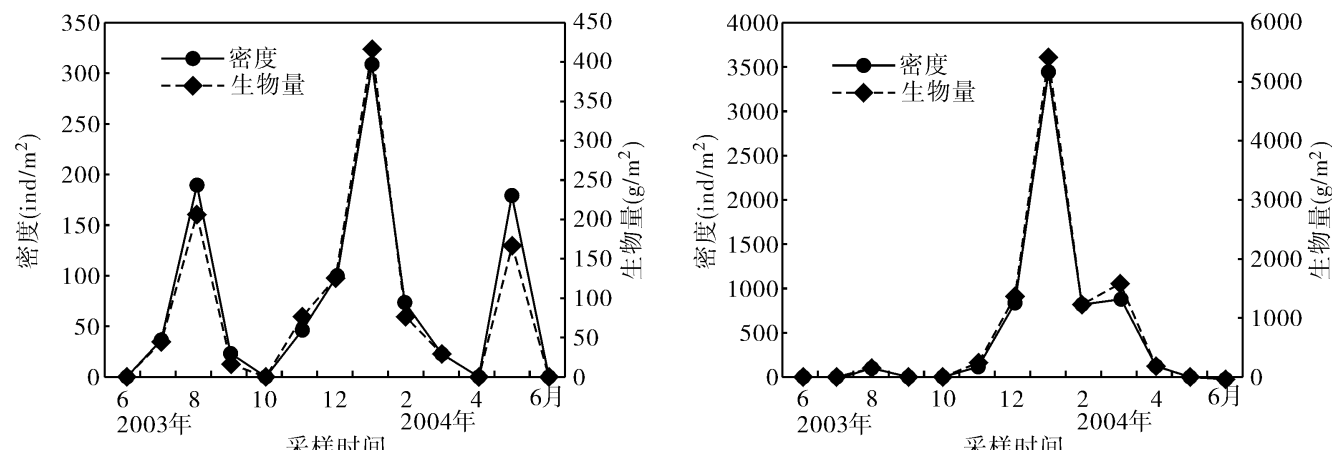

杂色特维摇蚊

采样时间

波特真开氏摇蚊

采样时间

图 6 主要优势种的生物量 (湿重) 周年动态

Fig. 6 Annual variations of standing stocks (wet weight) of dominant species 


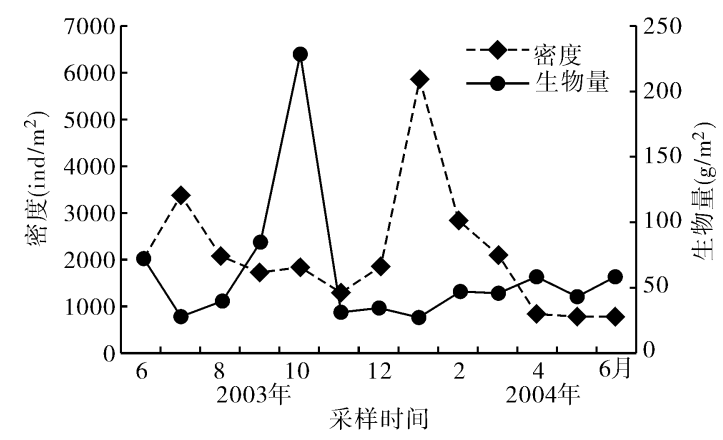

图 7 黑竹冲河大型底栖动物群落现存量的周年动态

Fig. 7 Annual variation of standing stock of macrozoobenthos in Heizhuchong stream

游 $100 \mathrm{~m}$, 所采集到的物种数和物种多样性较其它各采样点的均小; 而样点 $4\left(\mathrm{~S}_{4}\right)$ 比其它采样点生长着更 多的水生植物, 改变了生态系统的空间结构, 增加了空间的异质性, 所采集到的物种数和物种多样性较其它 采样点的均大. 这与董哲仁 ${ }^{[8]}$ 的结论相一致.

我国对河流生物多样性的研究多与河流水质评价或污染监测联系在一起, 反映的结果多为污染河流的 生物多样性, 缺少对清洁河流本底状况的研究. 相比已报道的有关河流的底栖动物群落多样性 ${ }^{[9]}$, 黑竹冲 河的物种数和生物多样性均较高. 目前, 我国河流的污染状况呈恶化趋势, 加强对不同类型河流的生态学 研究显得更加必要而迫切.

\section{4 参考文献}

[1] Benke A C. Baldi Memorial Lecture: Concepts and patterns of invertebrate production in running waters. Ver Internat Verein Limnol, 1993, 25:15 - 38.

[2] Covich A P, Palmer M A, Crowl T A. The role of benthic invertebrate species in freshwater ecosystems. BioScience, 1999,49 (2):119-127.

[3] 马克平. 生物群落多样性的测度方法. 见: 钱迎情, 马克平编. 生物多样性研究的原理与方法. 北京: 中国科学技术出版社, 1994: $141-165$.

[4] Wu J H, Liang Y L. A comparative study of benthic nematodes in two Chinese lakes with contrasting sources of primary production. Hydrobiologia, 1999, 411:31-37.

[5] Wetzel R G. Limnology (second edition). Philadelphia: Saunders College Publishing, 1983.

[6] Barbour M T, Gerritsen J, Griffith G E et al. A framework for biological criteria for Florida streams using benthic macroinvertebrates. Journal of North American Benthology Society, 1996, 15 (2) : 185 - 211.

[7] 于 力, 于海燕, 王 霞. 监测和评价浑江水质的底栖动物指标体系研究. 中国环境监测, 2002, 18 (6) : $59-63$.

[8］董哲仁. 河流形态多样性与生物群落多样性. 水利学报, 2003, 11: 1-7.

[9] 王建国, 黄恢柏, 杨明旭等. 庐山地区底栖大型无脊椎动物耐污值与水质生物学评价. 应用与环境 生物学报, 2003, 9 (3): $279-284$. 